\title{
Hirayama disease
}

\author{
Chaitra Badve $\cdot$ Sumit Pruthi
}

Received: 24 July 2009 /Revised: 23 September 2009 /Accepted: 9 November 2009/Published online: 8 December 2009

(C) Springer-Verlag 2009

(Editor's note: Pediatric Radiology restricts content to diseases and conditions of childhood, but there are conditions in young adults that clearly originate in childhood. These conditions are important for pediatric radiologists to recognize and publication is within the scope of the journal and its mission to readers.)

A 24-year-old man was investigated for weakness in upper limbs. MRI cervical spine flexion views revealed anterior displacement of posterior dura (arrow) with multiple flow voids and effacement of the CSF space at multiple levels (arrow) (Figs. 1 and 2). The cord was normal. Hirayama disease, also known as juvenile muscular

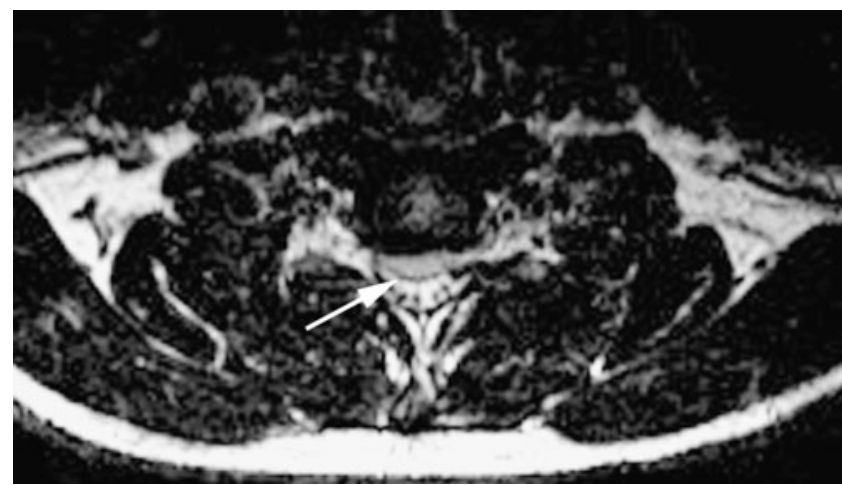

Fig. 2 Axial T2-W image of the spine

atrophy, is seen in males in the 2nd and 3rd decades of life. The proposed cause is dynamic compression of the cord seen only at neck flexion with forward displacement of posterior dura secondary to disproportional lengths of the vertebral column and the dural canal [1]. Later stages might show asymmetric flattening or ischemic atrophy of the spinal cord caused by repeated flexion. Avoiding flexion stops disease progression; hence, early diagnosis is crucial [2]. Flexion MRI should be considered in children with asymmetric cervical myelopathy, because conventional or extension views might show no specific abnormality. Management options vary from cervical collar to decompression to duraplasty.

\section{References}

C. Badve $\cdot$ S. Pruthi $(\bowtie)$

Department of Radiology, R-5417, Seattle Children's Hospital \& University of Washington Medical Center,

4800 Sand Point Way NE,

Seattle, WA 98105, USA

e-mail:sumitp@u.washington.edu
1. Hirayama K, Tokumaru Y (2000) Cervical dural sac and spinal cord in juvenile muscular atrophy of distal upper extremity. Neurology 54:1922-1926

2. Chen CJ, Chen CM, Wu CL et al (1998) Hirayama disease: MR diagnosis. AJNR 19:365-368 